\title{
Research of Silicon Waste Processing Products as Ultradispersed Activating Fluxes of Arc Welding
}

\author{
Nikolai N. Ivanchik, Andrey E. Balanovsky, \\ Victor V. Kondratyev and Andrey A. Tyutrin* \\ Irkutsk National Research Technical University \\ 83 Lermontov Str., Irkutsk, 664074, Russia
}

Received 26.01.2017, received in revised form 29.09.2017, accepted 04.01.2018

SUMMARY. GOAL. Obtain experimental data on the effect of ultrafine silica particles in the welding arc, its penetrating power. METHODS. The arc of DC straight polarity with the current strength in the range 70-400 A burned vertically between tungsten non-consumable electrode (diameter 2.4-4 mm) and the metal surface in inert argon gas (TIG welding). The welding experiments were performed on plates measuring $150 \times 50 \times(2,4,6) \mathrm{mm}$ mild steel 3 . Before the A-TIG welding was applied on the surface of the wafer uniform controlled flux activating layer (SiO2-silica) with a width of $5 \mathrm{~mm}$ and a thickness of 20 microns. Three flux with different fractional composition were used. RESULTS AND ITS DISCUSSION. The voltage on the arc in the pure argon was $12-15 \mathrm{~V}$, in pure argon using a flux activating $16-20 \mathrm{~V}$, welding a gas mixture (30\% argon + helium) without activating the flux voltage was 20-26 V. According to the thermal power in argon arc welding with flux-activating approaches the welding arc in a gas mixture, but at its superior penetrating power. The stitches are formed deep and narrow, wedge-shaped. CONCLUSIONS. The use of activating flux of ultrafine silica leads to the maximum the penetrating arc capacity by increasing the effective heat capacity of the welding heat source. As a result of applying the proposed composition of the activating flux penetrating power of the welding arc has increased by 2-4 times, the energy intensity of the process has decreased by 30-50\%.

Keywords: waste recycling, resource conservation, activating flux, arc welding, nanosilica.

Citation: Ivanchik N.N., Balanovsky A.E., Kondratyev V.V., Tyutrin A.A. Research of silicon waste processing products as ultradispersed activating fluxes of arc welding, J. Sib. Fed. Univ. Eng. technol., 2018, 11(2), 155-167. DOI: 10.17516/1999494X-0019.

(C) Siberian Federal University. All rights reserved

* Corresponding author E-mail address: nickolayivanchik@gmail.com,kvv@istu.edu 


\title{
Исследования продуктов переработки отходов кремния \\ в качестве ультрадисперсных активирующих флюсов \\ для дуговой сварки
}

\author{
Н.Н. Иванчик, А.Е. Балановский, \\ В.В. Кондратьев, А.А. Тютрин \\ Иркутский национальный \\ исследовательский технический университет \\ Россия, 664074, Иркутск, ул. Лермонтова, 83
}

Нашей целью было получение экспериментальных данных о влиянии ультрадисперсных частиц кремнезема на сварочную дугу, ее проплавляющую способность.

Сварочная дуга постоянного тока прямой полярности с силой тока в пределах 70-400 A горела вертикально между вольфрамовым неплавящимся электродом (диаметр - 2,4-4 мм) и поверхностью металла в среде защитного газа аргона (TIG welding). Сварочные эксперименты выполняли на пластинах размером $150 \times 50 \times(2,4$, 6) мм из малоуглеродистой стали 3. Перед А-ТИГ-сваркой на поверхность пластины наносили равномерный контролируемый слой активирующего флюса - $\mathrm{SiO}_{2}$ (диоксид кремния) шириной 5 мм и толщиной 20 мкм. Использовались три флюса с различным фракиионным составом.

Напряжение на дуге в чистом аргоне составляло 12-15 В; в чистом аргоне с использованием активирующего флюса-16-20 B; при сваркев смесигазов (аргон $+30 \%$ гелия) без активирующего флюса напряжение равнялось 20-26 В. По тепловой мощности сварочная дуга в аргоне с активируюшим флюсом приближсается к сварочной дуге в смеси газов, но по проплавляющей способности превосходит ее. Швы формируются узкими и глубокими клинообразной формы. Использование активирующего флюса из ультрадисперсного диоксида кремния приводит к максимальной проплавляющей способности сварочной дуги за счет повышения эффективной тепловой мощности сварочного источника нагрева. В результате использования разработанного состава активирующего флюса проплавляющаяся способность сварочной дуги увеличилась в 2-4 раза, энергоемкость процесса снизилась на 30-50\%.

Ключевые слова: переработка отходов, ресурсосбережение, активирующий флюс, дуговая сварка, нанокремнезем.

\section{Введение}

Сварка неплавящимся электродом (TIG welding) признана одним из ведущих технологических процессов при изготовлении конструкций ответственного назначения из цветных металлов и сплавов, высоколегированных и высокопрочных сталей. Она позволяет получать соединения высокого качества из сталей различных марок, в том числе высоколегированных, алюминия, титана, меди, никеля и других цветных металлов и сплавов. Одной из причин, сдерживающих применение аргонодуговой сварки металлов большой толщины, служит ее низкая производительность, ограниченная сравнительно невысокой тепловой эффективностью дуги и нарушением формирования швов. В связи с этим одним из приоритетных направлений развития сварки неплавящимся электродом является повышение ее производительности [1]. Традиционное решение данной проблемы предполагает увеличение количества металла, наплавляемого в единицу времени [1-3]. Это обусловлено ограниченной проплавляющей способностью дуги, в результате чего детали толщиной 3 мм и более рекомендуется сваривать с предварительной 
разделкой кромок [1-3], которую необходимо заполнять. Наиболее простой и доступный путь решения данной задачи при дуговой сварке - увеличение скорости плавления электрода за счет повышения сварочного тока [1]. Однако при этом увеличивается тепловложение в сварное соединение, что даже при сварке низкоуглеродистых сталей, отличающихся высокими показателями свариваемости, может привести к перегреву металла, росту аустенитного зерна и повышению хрупкости сварного соединения [1-5]. При сварке сталей, склонных к закалке, это сопровождается еще и снижением стойкости к образованию трещин [4]. Кроме всего, сварка на повышенных токах увеличивает энергоемкость, что требует применения специальных источников тока и влияет на себестоимость процесса. С учетом сказанного выше для решения данной задачи требуется принципиально иной подход - увеличение глубины проплавления [1]. Достичь этого можно путем повышения проплавляющей способности дуги за счет уменьшения диаметра электродной проволоки (повышается плотность тока и, как следствие увеличивается скорость плавления металла) [1] либо применения активирующих флюсов (активация дуги-A TIG welding) [2-11].

В сварочной литературе нет определения термина «активирующий флюс». В ГОСТ РИСО 857-1-2009 «Сварка и родственные процессы. Словарь. Часть 1. Процессы сварки металлов. Термины и определения» дано следующее определение: «Сварочный флюс-материал, используемый при сварке для химической очистки соединяемых поверхностей и улучшении качества шва». Применительно к сварочным процессам под термином «активирующий флюс», или «активирующая среда», подразумевают $[3,4]$ газообразное, жидкое или твердое вещество, состоящее из солей, галогенидных соединений и оксидов, которое водится при сварке в зону горения дуги и плавления металла в целях комплексного влияния на сварочную ванну и дуговой разряд, которое выражается в увеличении глубины проплавления, улучшении формирования и качества сварных соединений. Под термином «активирующий материал» понимают металлический или неметаллический сварочный материал, в состав которого входит активирующий флюс [4]. Активирующий материал позволяет использовать активирующее воздействие с получением дополнительного экономического эффекта за счет увеличения производительности, точности, качества сборочных и сварочных операций, улучшения формирования и качества сварных соединений. В свою очередь активирующий материал в большинстве своем продукт высокотехнологичный либо произведен из дорогих материалов [4], невозобновляемых природных ресурсов, чьи запасы исчерпываются. Соответственно, стоимость извлечения целевых продуктов из природного сырья также увеличивается, что отражается на конечной стоимости всей продукции. Это побуждает производителей рассматривать альтернативные источники целевых продуктов, например вторичное сырье. Задача их извлечения может вызывать большие трудности как технологического, так и экономического плана [12]. Например [13, 14], основными производителями вторичного сырья, состоящего из солей, галогенидных соединений и оксидов, в Иркутской области являются металлургические предприятия по выпуску алюминия и кремния и предприятия энергетического сектора. Наибольшие объемы производимого вторичного сырья дают смесь пыли и шламов газоочистки, кремниевая пыль и золошлаковая смесь соответственно [13, 14]. Составы данных видов вторичного сырья приведены в табл. 1. Данные по отходам ТЭЦ Иркутской области могут различаться в зависимости от конкретной ТЭЦ и состава сжигаемого угля; здесь приведены данные крупнейшей ТЭЦ Иркутска - Ново-Иркутской

$$
-157-
$$


Таблица 1. Химический состав основных производственных отходов Иркутской области, содержание компонентов, масс. \%

Tadle 1. Chemical composition of the main industrial waste of the Irkutsk region values, mass \%

\begin{tabular}{|l|c|c|c|c|c|c|c|c|c|c|c|c|c|c|}
\hline \multicolumn{1}{|c|}{$\begin{array}{l}\text { Наименование } \\
\text { отхода }\end{array}$} & \multicolumn{10}{|c|}{ Химический состав } \\
\cline { 2 - 13 } & $\mathrm{SiO}_{2}$ & $\mathrm{Al}_{2} \mathrm{O}_{3}$ & $\mathrm{Fe}_{2} \mathrm{O}_{3}$ & $\mathrm{CaO}$ & $\mathrm{MgO}$ & $\mathrm{Na}_{2} \mathrm{O}$ & $\mathrm{SO}_{4}{ }^{2-}$ & $\mathrm{SO}_{3}$ & $\mathrm{~F}-$ & $\mathrm{P}_{2} \mathrm{O}_{5}$ & $\mathrm{~K}_{2} \mathrm{O}$ & $\mathrm{TiO}_{2}$ & $\mathrm{SiC}$ & П.п. \\
\hline $\begin{array}{l}\text { Шламы } \\
\text { газоочистки } \\
\begin{array}{l}\text { производства } \\
\text { алюминия }\end{array}\end{array}$ & 0,24 & 18,54 & 3,7 & 0,79 & 0,32 & 23,02 & 3,13 & & 26,01 & - & - & - & - & 24,25 \\
\hline $\begin{array}{l}\text { Пыль } \\
\text { производства } \\
\text { кремния }\end{array}$ & 85,41 & 0,46 & 0,30 & 1,50 & 1,24 & 0,08 & - & 0,16 & - & 0,12 & 0,31 & 0,02 & 5,03 & - \\
\hline $\begin{array}{l}\text { Золошлаковая } \\
\text { смесь ТЭЦ }\end{array}$ & 55,0 & 28,7 & 6,9 & 5,5 & 1,6 & 0,2 & - & 0,5 & - & - & 0,8 & 0,8 & - & 3,9 \\
\hline
\end{tabular}

ТЭЦ) $[13,14]$. При изучении составов активирующих флюсов было отмечено, что многие из них [14] содержат кремнезем, причем чаще всего мелкодисперсный - при изготовлении флюса вещества специально измельчаются до крупности менее 50 мкм.

Благодаря технологии флотационного обогащения наноразмерных сред [13] из отходов системы газоочистки производства кремния удалось выделить гранулы $\mathrm{SiO}_{2}$, фракционный состав которых представляет особый интерес, поскольку большая часть частиц размером не превышают микрометра. Доказан размерный эффект частиц на самые разные типы систем [15]. Богатый опыт в выделении и использовании $\mathrm{SiO}_{2}$ из отходов производства [13-15] позволил авторам статьи подойти к следующему решению - проверить гипотезу о положительном влиянии ультрадисперсного кремнезема на проплавляющую способность дуги. Поэтому целью работы является оценка возможности повышения производительности и снижения энергоемкости сварки в среде защитных газов.

Оборудование и материалы. Для проведения исследований сварочная дуга постоянного тока прямой полярности силой тока в пределах 70-400 А горела вертикально между вольфрамовым неплавящимся электродом (диаметром 2.4-4 мм) и поверхностью металла в среде защитного газа аргона (TIG welding). Сварочные эксперименты выполняли на пластинах размером $150 * 50 *(2,4,6)$ мм из малоуглеродистой стали 3 . Перед А-ТИГ-сваркой на поверхность пластины наносили равномерный контролируемый слой активирующего флюса ( $\mathrm{SiO}_{2}$ - диоксида кремния) шириной 5 мм и толщиной 20 мкм. Толщину слоя активатора контролировали специальным толщиномером ТП-34 на основе вихретокового преобразователя. Данные условия проведения эксперимента соответствуют реальному технологическому процессу сварки неплавящимся электродом (вольфрам) в среде защитного газа (аргон) на постоянном токе, который используется в промышленности для сварки изделий из стали, алюминия, меди, титана. Для сравнения результатов и выявления положительного эффекта применяли в качестве плазмообразующего газа аргон и смесь газов: аргон и 30 \% гелия. В качестве источника питания выступал промышленный источник тока для сварки с напряжением холостого хода 70 В и максимальным током 450 А. Процесс горения дуги фиксировался цифровой зеркальной камерой -á SONY 350 и высокоскоростной камерой PCO.1200с по мето-

$$
-158-
$$


дике, изложенной в работе [16]. Для измерения тока и напряжения использовался цифровой осциллограф Tektronix TDC-1012B.

Известно [13], что при производстве кремния на 1 т металла образуется более 700 кг пыли. Основными компонентами пыли являются двуокись кремния $\mathrm{SiO}_{2}$, не восстановленная до $\mathrm{Si}$ в процессе электротермического производства кремния, и углерод, в основном в свободном состоянии. Технологическая пыль имеет следующий химический состав:

\begin{tabular}{|c|c|c|c|}
\hline & мас. \% & & мас. $\%$ \\
\hline \multirow[t]{2}{*}{$\mathrm{SiO}_{2}$} & $75 \div 95$ & в пересчете на O & $39,9 \div 50,5$ \\
\hline & & в пересчете на $\mathrm{Si}$ & $35,1 \div 44,5$ \\
\hline \multirow[t]{2}{*}{$\mathrm{SiC}$} & $4,0 \div 11,0$ & в пересчете на $\mathrm{Si}$ & $2,8 \div 7,7$ \\
\hline & & в пересчете на С & $1,2 \div 3,3$ \\
\hline $\mathrm{C}_{\text {своб. }}$. & $3,0 \div 7,0$ & & \\
\hline \multirow[t]{2}{*}{$\mathrm{CaO}$} & $1,0 \div 2,0$ & в пересчете на Са & $0,72 \div 1,43$ \\
\hline & & в пересчете на O & $0,28 \div 0,57$ \\
\hline \multirow[t]{2}{*}{$\mathrm{MgO}$} & $0,4 \div 1,2$ & в пересчете на O & $0,16 \div 0,48$ \\
\hline & & в пересчете на Mg & $0,24 \div 0,72$ \\
\hline \multirow[t]{2}{*}{$\mathrm{Al}_{2} \mathrm{O}_{3}$} & $0,5 \div 1,0$ & в пересчете на Al & $0,27 \div 0,53$ \\
\hline & & в пересчете на O & $0,23 \div 0,47$ \\
\hline \multirow[t]{2}{*}{$\mathrm{Fe}_{2} \mathrm{O}_{3}$} & $0,3 \div 0,9$ & в пересчете на Fe & $0,21 \div 0,63$ \\
\hline & & в пересчете на О & $0,09 \div 0,27$ \\
\hline
\end{tabular}

Прочее, (в том числе фосфор)

$0,8 \div 2,3$

Для изготовления активирующего флюса использовали пыль газоочистки электротермического производства кремния, содержащую компоненты в следующем соотношении [13], мас. \%: $\mathrm{SiO}_{2} 75 \div 95, \mathrm{SiC} 4,0 \div 11,0, \mathrm{C}_{\text {своб }} 3,0 \div 7,0, \mathrm{MgO} 0,4 \div 1,2, \mathrm{Al}_{2} \mathrm{O}_{3} 0,5 \div 1,0, \mathrm{Fe}_{2} \mathrm{O}_{3} 0,3 \div 0,9, \mathrm{CaO}$ $1,0 \div 2,0$, прочее $0,8 \div 2,3$. Гранулометрический состав исходной композиции для приготовления активирующего флюса (микрокремнезем) имел следующий фракционный диапазон:

$\begin{array}{cc}\text { Фракция, мкм } & \text { Массовая доля, \% } \\ 0 \div 0,1 & 0,2 \div 0,3 \\ 0,1 \div 1,0 & 12,0 \div 15 \\ 1,0 \div 3,0 & 13,0 \div 17,0 \\ 3,0 \div 5,0 & 9,0 \div 11,0 \\ 5,0 \div 10,0 & 8,0 \div 10,0 \\ 10,0 \div 20,0 & 12,0 \div 20,0 \\ 20,0 \div 30,0 & 5,0 \div 7,0 \\ 30,0 \div 100,0 & 1,0 \div 3,0\end{array}$

Для проведения исследований было приготовлено несколько активирующих гранулометрических составов шихты (табл. 2). Первый состав имел размер частиц 150-300 мкм (макрокремнезем). Второй состав имел размер частиц не выше 100 мкм и, по мнению авторов работ [2-10], был наиболее эффективен с точки зрения максимального активирующего воздействия в сварочной дуге. Третий состав активирующего флюса (нанокремнезем) был представлен соединениями кремния ультрадисперсной фракции на уровне наночастиц 4080 нм [15].

$$
-159-
$$


Таблица 2. Физические свойства активирующего флюса

Table 2. Physical properties of the activating flux

\begin{tabular}{|l|c|c|c|}
\hline \multirow{2}{*}{\multicolumn{1}{|c|}{ Свойства }} & \multicolumn{3}{|c|}{ Активирующий флюс } \\
\cline { 2 - 4 } & Макрочастицы $\mathrm{SiO}_{2}$ & Микрочастицы $\mathrm{SiO}_{2}$ & Наночастицы $\mathrm{SiO}_{2}$ \\
\hline Размер частиц & $200-300$, мкм & $30-70$, мкм & $40-80$, нм \\
\hline Насыпная плотность, г/см & 2,64 & 2,42 & 2,10 \\
\hline
\end{tabular}

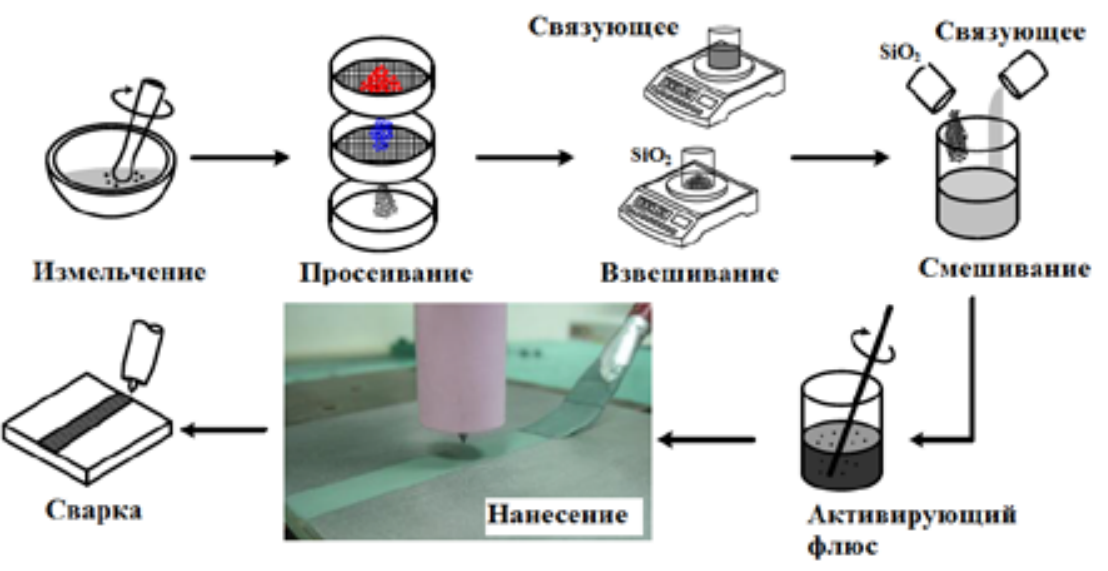

Рис. 1. Схема подготовки и нанесения активирующего флюса

Fig. 1. Preparation scheme and infliction of the activating flux

Подготовка активирующего флюса и порядок нанесения состоит из нескольких технологических операций и схематично изображен на рис. 1.

Результаты исследований и обсуждение. На рис. 2 представлены результаты фотографирования процесса сварки без активирующего флюса (рис $2 a$ ) и с активирующим флюсом (рис. 26,6). Фотографирование процесса показывает, что передняя и хвостовая части поверхности сварочной ванны при А-ТИГ сварке с активирующим флюсом имеют форму с четко выраженным характерным углублением (лункой) вблизи центра кратера (рис. 26,6). Такого существенного углубления при ТИГ-сварке без активирующего флюса не наблюдается (рис. $2 a$ ). Наоборот, мы видим ровную поверхность жидкой ванны в площади пятна нагрева. С повышением тока дуги при сварке с активирующими флюсами глубина этой лунки увеличивается при использовании всех исследуемых толщин образцов. Известно, что для интенсивного испарения металла его поверхность необходимо нагреть источником, имеющим плотность теплового потока в пятне нагрева порядка $1 \cdot 10^{5} \ldots 1 \cdot 10^{6} \mathrm{BT} / \mathrm{cm}^{2}[17,18]$. В процессах сварки с использованием активирующих флюсов вследствие контрагирования дуги на сварочном токе 200 А плотность теплового потока составляет $1 \cdot 10^{4} \mathrm{BT} / \mathrm{cm}^{2}$ и выше [3, 4].

Полученные нами результаты свидетельствуют об эффективности увеличения проплавляющей способности дуги за счет уменьшения диаметра анодного пятна сварочной дуги. Активирующий флюс, который вводится в зону сварки, инициирует сжатие дуги и повышение

$$
-160-
$$




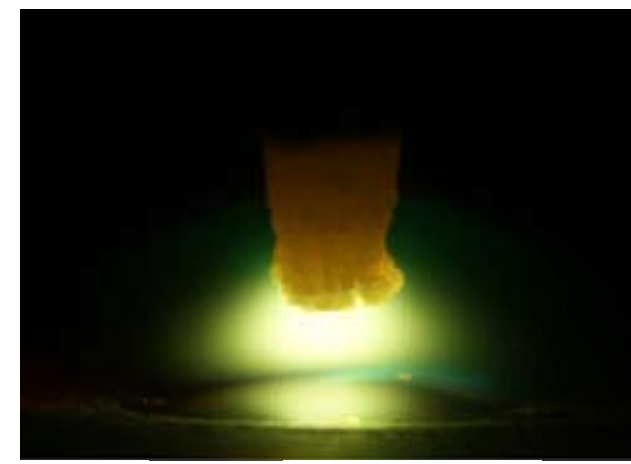

(a)

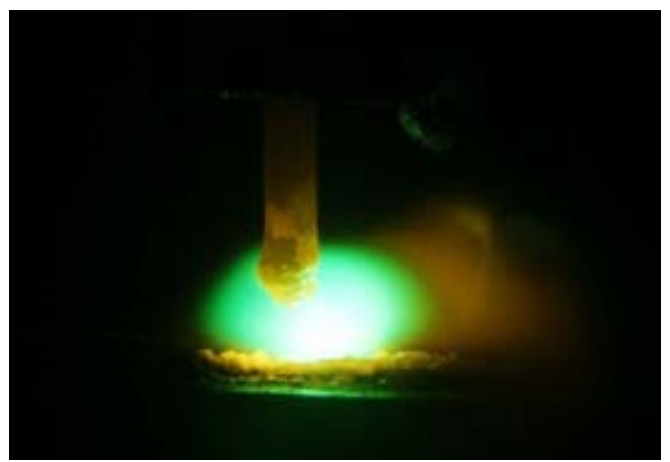

(б)

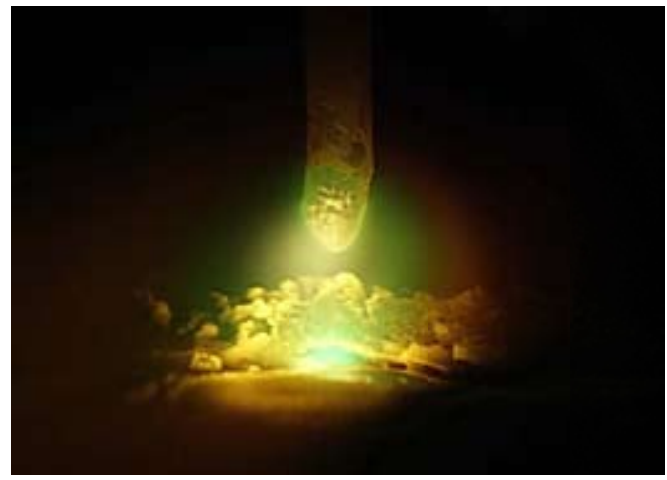

(B)

Рис. 2. Изменение строения сварочной дуги при аргонодуговой сварке пластин из стали толщиной 4 мм: $\mathrm{a}$ - без флюса; б, в - по активирующему флюсу- $\mathrm{SiO}_{2}$. Сила постоянного тока прямой полярности $100 \mathrm{~A}$. Длина дуги 2 мм. Скорость сварки 14 см/мин

Fig.2. The change in the structure of the welding arc during argon-arc welding of steel plates with a thickness of $4 \mathrm{~mm}$ : a - without flux; б, в - by the activating flux- $\mathrm{SiO}_{2}$ (experimental conditions: DC current (straight polarity) $100 \mathrm{~A}$, arc length $2 \mathrm{~mm}$, welding speed $15 \mathrm{~cm} / \mathrm{min}$ )

плотности тока в ней. В результате повышается концентрация нагрева и увеличивается газодинамическое давление дуги на сварочную ванну, что сопровождается увеличением проплавляющей способности дуги и глубины проплавления. Эффект увеличения проплавляющей способности дуги определяется системой взаимосвязанных процессов, происходящих в сварочной ванне, столбе дуги и околодуговом пространстве. При плавлении флюса на поверхности сварочной ванны образуется экранирующая шлаковая фаза (рис. 26) с низкой электропроводностью, которая снижает поверхностное натяжение расплавленного металла и увеличивает прогиб сварочной ванны. Давление электрической дуги на поверхность сварочной ванны при увеличении ее прогиба приводит к вытеснению расплавленного металла и уменьшению толщины жидкой прослойки под дугой, теплопередача при этом улучшается, а глубина проплавления увеличивается. Экранирование сварочной ванны шлаком с низкой электропроводностью вызывает уменьшение диаметра анодного пятна, в результате чего плотность тока в нем резко возрастает. При этом общее электропроводное сечение столба дуги уменьшается, а концентрация тепловой энергии и плотность тока в нем значительно увеличиваются. Сжатие анодного 


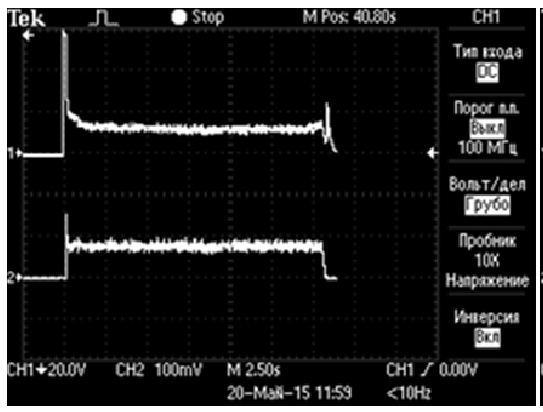

(a)

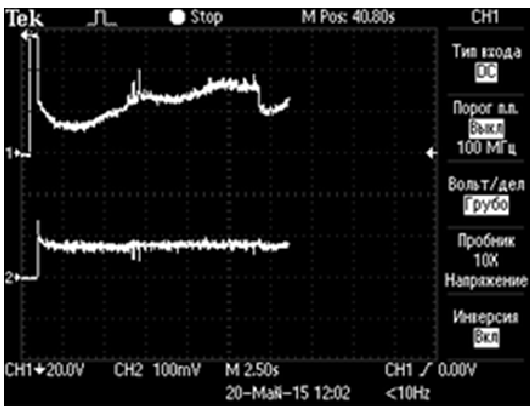

(б)

Рис. 3. Осциллограммы тока и напряжения сварочной дуги: a - без флюса; б - с флюсом

Fig.3. Oscillograms of current and voltage of the welding arc: a - without flux; $\sigma$ - with flux

пятна и контрагирование столба дуги приводят к сосредоточению энергии в анодном пятне и увеличению глубины проплавления. На рис. 3 приведены осциллограммы, показывающие увеличение напряжения при сварке с активирующим флюсом при равных значениях тока. Эти результаты свидетельствуют об увеличении эффективной тепловой мощности сварочной дуги при сварке с использованием активирующего флюса.

В то же время известно, что напряжение дуги в гелии в $15-2$ раза выше, чем в аргоне; при одном и том же токе при сварке в среде гелия выделяется больше тепла, чем при сварке в аргоне; проплавляющая способность дуги в гелии также выше, чем в аргоне $[1,11]$. В нашем случае напряжение на дуге в чистом аргоне составляло 12-15 В, в чистом аргоне с использованием активирующего флюса - 16-20 В, при сварке в смеси газов( аргон $+30 \%$ гелия) без активирующего флюса напряжение равнялось 20-26 В. По тепловой мощности сварочная дуга в аргоне с активирующим флюсом приближается к сварочной дуге в смеси газов, но по проплавляющей способности превосходит ее. Повышение проплавляющей способности дуги при сварке с активирующим флюсом изменяет условия формирования сварных швов. Швы формируются узкими и глубокими, клинообразной формы (рис. 4). Отношение ширины к глубине (коэффициент формы шва) в наших экспериментах составлял $0,5-1,5$, что в $2,5-3$ раза меньше чем при сварке без активирующего флюса. По всей видимости, повышенная проплавляющая способность обусловлена концентрацией теплового потока в пятне нагрева или коэффициента сосредоточенности теплового источника $[1,11]$. Этот вопрос до сих пор остается дискуссионным, более подробно рассмотрен в работах [3-10] и не является предметом обсуждения нашей работы. В ходе экспериментов установлено (рис. 5), что размер частиц активирующего флюса играет существенную роль на проплавляющую способность сварочной дуги. Все три исследованных нами состава активирующих флюсов показывают положительный эффект на проплавляющую способность сварочной дуги. По сравнению с макро- и микрочастицами $\mathrm{SiO}_{2}$ наночастицы $\mathrm{SiO}_{2}$ имеют большую эффективность в проплавляющей способности при сварке с активирующим флюсом (рис. 58). В режиме дугового нагрева и испарения термическая диссоциация и разложение наночастиц диоксида кремния $\mathrm{SiO}_{2}$ происходят гораздо быстрее, чем термическая диссоциация и разложение микрочастиц диоксида кремния $\mathrm{SiO}_{2}$. В результате наноча- 


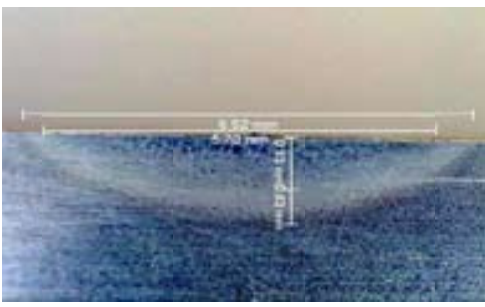

(a)

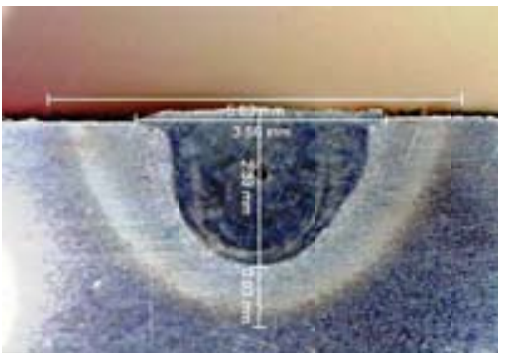

(б)

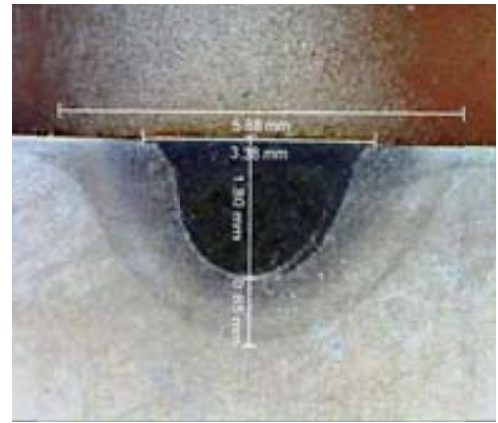

(c)

Рис. 4. Поперечный разрез зоны проплавления при сварке в аргоне (условия эксперимента: сила постоянного тока прямая полярность -80 А, длина дуги - 2 мм, скорость сварки - 18 см/мин): а - без активирующего флюса; б - с активирующим флюсом (нанокремнезем) связующее этиловый спирт; в - с активирующим флюсом (нанокремнезем), связующее - термостойкий лак

Fig.4 Cross-section of the fusion zone during welding in argon (experimental conditions: DC current (straight polarity) $-80 \mathrm{~A}$, arc length $-2 \mathrm{~mm}$, welding speed $-18 \mathrm{~cm} / \mathrm{min}$ ): a - without the activating flux, 6 - with an activating flux (nanosilica), a binder - ethyl alcohol, B - with an activating flux (nanosilica), a binder - heat-resistant varnish

стицы диоксида кремния $\mathrm{SiO}_{2}$ при сварке оказывают большое влияние на проплавляющие способности дуги по сравнению с микрочастицами диоксида кремния $\mathrm{SiO}_{2}$, что приводит к увеличению глубины проплавления на 50-70\%.

На рис. 6 представлены обобщающие результаты положительного эффекта использования активирующего флюса при сварке низкоуглеродистой стали в среде аргона по сравнению со сваркой без активирующего флюса как в среде аргона, так и в смеси газов (аргон + гелий). Особенно сильно проявляется положительный эффект использования активирующего флюса на больших токах и с увеличением толщины металла. По технологии сварки мы видим (рис. 6), что для сварки металла толщиной 2,4 мм при использовании активирующего флюса возможно существенно снизить электрическую мощность сварочной дуги.

Полученные значения на рис. 6 находятся в хорошем качественном соотношении с результатами работ других авторов, которые рассматривали активирующие флюсы, где основным компонентом были оксиды металлов.

Представленные выше результаты исследований являются предварительными, так как в дальнейшем необходимо проделать большой объем работ и рассмотреть комплексно вопрос применения активирующих флюсов при сварке в защитных газах не только с позиции формоо- 


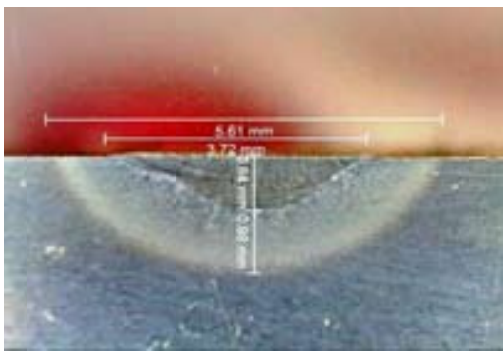

(a)

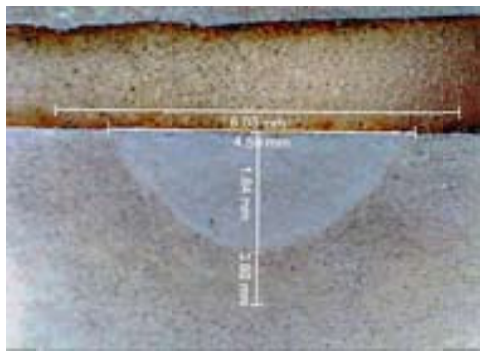

(б)

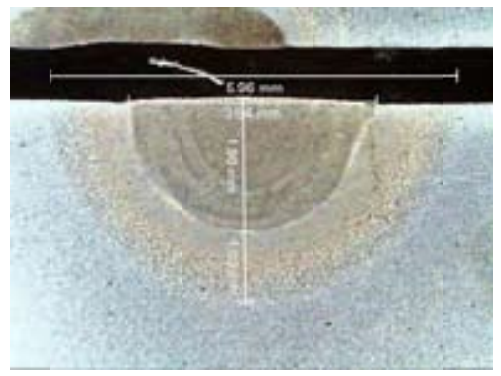

(B)

Рис. 5. Поперечный разрез зоны проплавления при сварке в аргоне (условия эксперимента: сила постоянного тока прямая полярность - 90А,длина дуги - 2 мм, скорость сварки - 25 см/мин): а активирующий флюс (макрокремнезем), связующее - термостойкий лак; б - активирующий флюс (микрокремнезем), связующее - термостойкий лак; в - активирующий флюс (нанокремнезем), связующее - термостойкий лак

Fig. 5 Cross-section of the fusion zone during welding in argon (experimental conditions: DC current (straight polarity) - 90A, arc length $-2 \mathrm{~mm}$, welding speed $-25 \mathrm{~cm} / \mathrm{min}$ ): a - activating flux (macrocosmic), binder - heatresistant varnish; 6 - activating flux (microsilica); binder - heat-resistant varnish; в - activating flux (nanosilica), binder - heat-resistant varnish

бразования сварного шва, но и с позиции структурообразования в зоне термического влияния и изменения механических свойств сварных изделий.

Таким образом, проведенные исследования показали, что использование отходов металлургического производства позволяет получать новые технологические материалы, которые по своим физико-химическим свойствам не уступают природным материалам. Сочетание исключительных теплофизических, механических и физико-химических свойств частиц нанокремнезема делает его уникальным материалом для многих отраслей техники и предопределяет такие основные направления применения, как материалы для модифицирующих [15] и активирующих составов флюсов в металлургии и машиностроения.

\section{Выводы}

1. Разработана технология получения целевого конечного продукта активирующего флюса для сварки из вторичного сырья - отходов металлургического производства [13].

2. По сравнению с традиционным способом применение активирующих флюсов обеспечивает уменьшение погонной энергии при однопроходной сварке металла одинаковой толщины до 3-5 раз по сравнению с традиционным способом. 


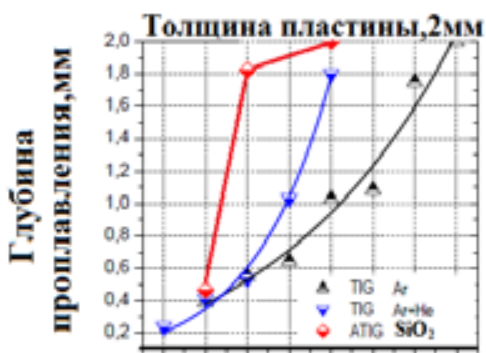

405060708090100110

Сила сварочного тока, $\mathrm{A}$

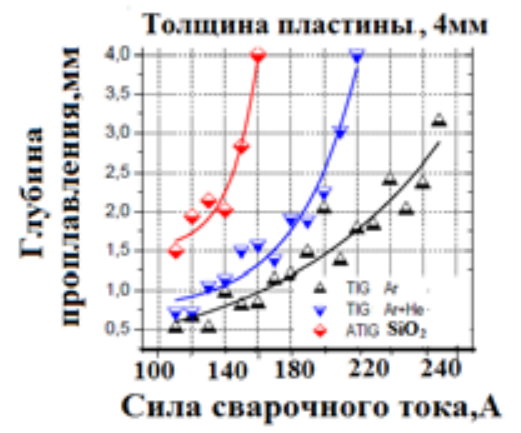

Сила сварочного тока, $\mathrm{A}$

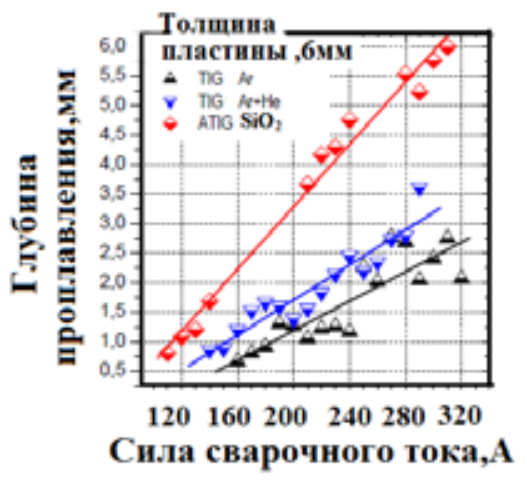

Рис. 6. Экспериментальные зависимости глубины проплавления стали Ст3 различной толщины от силы сварочного тока при различных режимах сварки (сварка в аргоне, в смеси газов, в аргоне с активирующим флюсом)

Fig. 6. Experimental dependences of the penetration depth of steel St3 with different thicknesses on the welding current at different welding regimes (welding in argon, in a mixture of gases, in argon with an activating flux)

3. Показано, что в режиме сварочно-дугового нагрева, испарения, термической диссоциации разложение наночастиц диоксида кремния $\mathrm{SiO}_{2}$ происходит быстрее, чем микро и макрочастиц диоксида кремния $\mathrm{SiO}_{2}$. С учетом этого факта расплав активирующего флюса, состоящий из наночастиц диоксида кремния $\mathrm{SiO}_{2}$ вытесняется потоком плазмы из-под основания столба дуги более интенсивно, а плазменный поток перемещает пар флюса вдоль границ столба дуги в катодную область. В дальнейшем, пар флюса распределяется по всему контуру дуги и проникает во все области за исключением центра столба дуги, который характеризуется высоким давлением и температурой. Пар флюса не влияет на электропроводимость центра столба дуги, а изменение технологических свойств дуги связано с процессам на границе дуги и в прианодной области, в виде сжатия активного пятна. Это приводит к увеличению плотности теплового потока в активном пятне дуги и максимальной проплавляющей способности сварочной дуги.

4. Использование активирующего флюса, имеющего в своем составе наночастицы диоксида кремния $\mathrm{SiO}_{2}$, при сварке в защитных газах позволяет увеличить проплавляющую способность дуги в 2-4 раза и повысить производительность сварки на пониженных токах. 


\section{Список литературы}

[1] Акулов А.И., Бельчук Г.А., Демянцевич В.П. Технология и оборудование сварки плавлением. М.: Машиностроение, 1977. 432 с. [Akulov A.I., Belchuk G.A., Demyantsevich V.P. Technology and equipment for fusion welding. $\mathrm{M}$.: Engineering, 1977. $432 \mathrm{p}$ (in Russian)].

[2] Савицкий М.М., Кушниренко Б.Н., Олейник О.И. Особенности сварки сталей вольфрамовым электродом с активирующими флюсами. Автоматическая сварка, 1999, 12, 20-28. [Savitsky M.M., Kouchnirenko B.N., Oleinik O.I., Features welded steel tungsten electrode with activating fluxes. Automatic welding. 1999, 12, $20-28$ (in Russian)].

[3] Паршин С.Г. Применение активирующих материалов при аргонодуговой сварке. Сварочное производство, 2003, 6, 40-43. [Parshin S.G. Application of activating materials under argon welding. Welding Engineering. 2003, 6, 40-43 (in Russian)].

[4] Паршин С.Г. Электродуговая сварка с применением активирующих флюсов. Самаpa: Самарский научный центр РАН, 2006. 380 с. [Parshin S.G. Arc welding using activating fluxes. Samara: Samara Science Centre of Russian Academy of Science, 2006. 380 p. (in Russian)].

[5] Savytsky O. [and others] Influece of the impurities on the depth of penetration with carbon steel weldings. Metalurgija, 2014, 2. 167-170.

[6] Niagaj J., Savytckyj M.M., Savytckyj O.M. The influence of activation on technological and ecological properties of welding arc under argon shield during welding of low - and high alloy steels. Biuletun instytutu spawalnictwa w gliwicach, 2008, 1, 46-50.

[7] Ленивкин В. А., Паршин С. Г. Влияние активизирующих галогеносодержащих покрытий проволоки на технологические свойства дуги при MIG-сварке. Сварочное производство, 2010, 10, 3-8. [Lenivkin V.A., Parshin S.G., Effect of activating halogen-coated wire on the technological properties of the arc at MIG-welding. Welding production, 2010, 10, 3-8 (in Russian)]

[8] Паршин, С. Г. Влияние ультрадисперсных частиц активирующих флюсов на процесс лазерной сварки. Сварочное производство, 2010, 2, 3-7. [Parshin S.G. Effect of ultrafine particles of activating fluxes on the laser welding process. Welding production, 2010, 2, 3-7 (in Russian)].

[9] Паршин, С. Г. Применение ультрадисперсных частиц активирующих флюсов с целью повышения производительности MIG/MAG-сварки сталей. Сварочное производство, 2011, 6, 16-21. [Parshin S.G. Application of ultrafine particles activating fluxes in order to increase productivity MIG / MAG-welding of steel. Welding production, 2011, 6, 16-21 (in Russian)].

[10] Паршин С. Г., Паршин С. C., Buerkner G. Повышение производительности WIG-сварки сталей и алюминиевых сплавов при введении ультрадисперсных частиц активирующих флюсов. Сварочное производство, 2012, 3, 7-11. [Parshin S.G., Parshin S.S., Buerkner G. Increased productivity WIG-welding of steels and aluminum alloys with the introduction of ultrafine particles activating fluxes. Welding production, 2012, 3, 7-11. (in Russian)].

[11] Балановский А.Е. Плазменное поверхностное упрочнение металлов. Иркутск: Изд-во ИрГТУ, 2006, 180 c. [Balanovsky А.E. Plasma surface hardening of metals. Irkutsk, Publishing House of Irkutsk State Technical University. 2006, 180 p. (in Russian)].

[12] Еромасов Р.Г., Никифорова Э.М., Спектор Ю.Е. Утилизация отходов алюминиевого производства в керамической промышленности. Журнал Сибирского Федерального Университета. Техника и технологии, 2012, 4, 442-453. [Eromasov R.G., Nikiforova E.M., Spector Y.E. 
Disposal of aluminum production in the ceramics industry. Journal of Siberian Federal University. Technics and technology, 2012, 4, 442-453. (in Russian)].

[13] Кондратьев В.В. [и др.] Теория и практика процессов флотационного обогащения наноразмерных сред. Иркутск: Изд-во Иркутского национального исследовательского технического университета, 2015, 160 с. [Kondratyev V.V. [Et al.] Theory and Practice of flotation of nanoscale environments. Irkutsk, Publishing House of Irkutsk State Technical University, 2015, 160 p. (in Russian)].

[14] Кондратьев В.В., Немчинова Н.В., Иванов Н.А., Сысоев И.А. Новые технологические решения по переработке кремниевого и алюминиевого производств, Металлург, 2013. 5. 9298. [Kondratyev V.V., Nemchinov N.V., Ivanov N.A., Sysoev I.A. New technological solutions for processing silicon and aluminum industries, Metallurgist, 2013, 5, $92-98$ (in Russian)].

[15] Кондратьев В.В., Балановский А.Е., Иванов Н.А., Ершов В.А., Корняков М.В. Оценка влияния состава модификатора с наноструктурными добавками на свойства серого чугуна. Металлург, 2014, 5. 48-56. [Kondratyev V.V., Balanovsky A.E., Ivanov N.A., Ershov V.A., Kornyakov M.V. Assessment of the impact modifier composition with nanostructured additives on the properties of cast iron. Metallurgist, 2014, 5, 48-56 (in Russian)].

[16] Балановский А.Е. Визуализация процесса нагрева и плавления металла в анодной области при дуговом разряде с неплавящимся электродом. ТВT, 2016, 54(5), 663-668. [Balanovsky A.Е. Visualization of the heating and melting process the metal in the anode region with the electric arc with consumable electrode. High Temperature, 2016, 54(5), 663-668. (in Russian)].

[17] Лесков В.Г. Электрическая сварочная дуга. М.: Машиностроение, 1970. 334c. [Leskov V.G. Electric arc welding. M., Mechanical engineering, 1970. 334 p. (in Russian)].

[18] Мазель А.Г. Технологические свойства сварочной дуги. М.: Машиностроение, 1969. 178 c. [Mazel A.G. Technological properties of the welding arc. M.: Mechanical Engineering, 1969. 178 p. (in Russian)]. 